\title{
Root production and methane dynamics: Impact of wetland functional group diversity and composition
}

Rachel Schultz, Virginie Bouchard and Serita Frey the
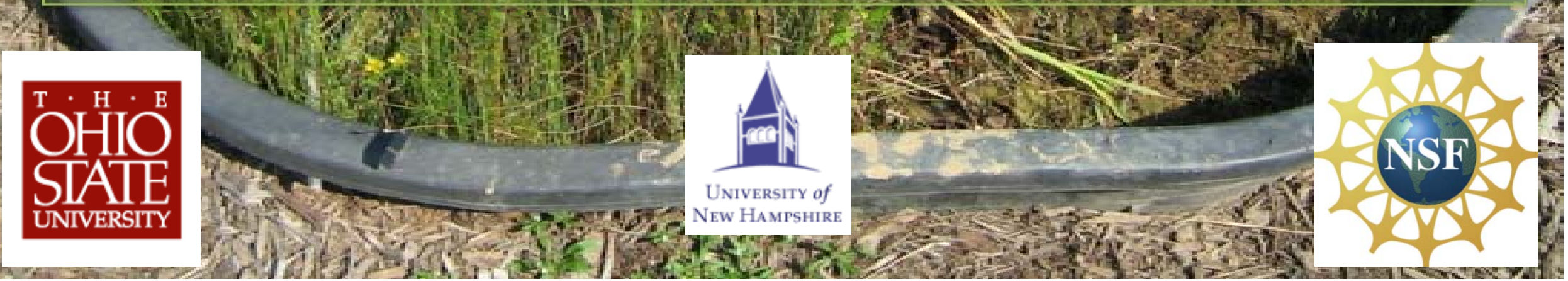


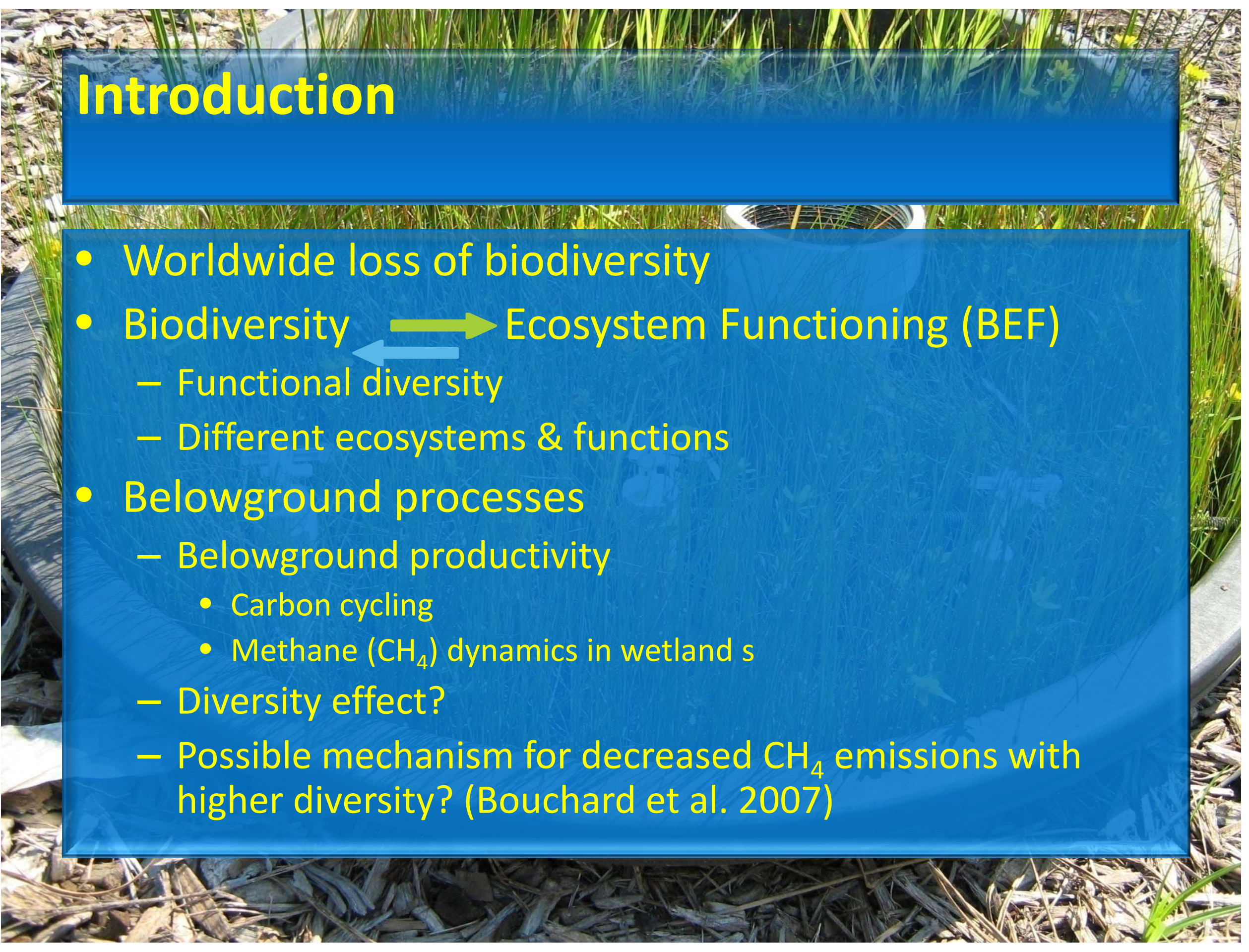




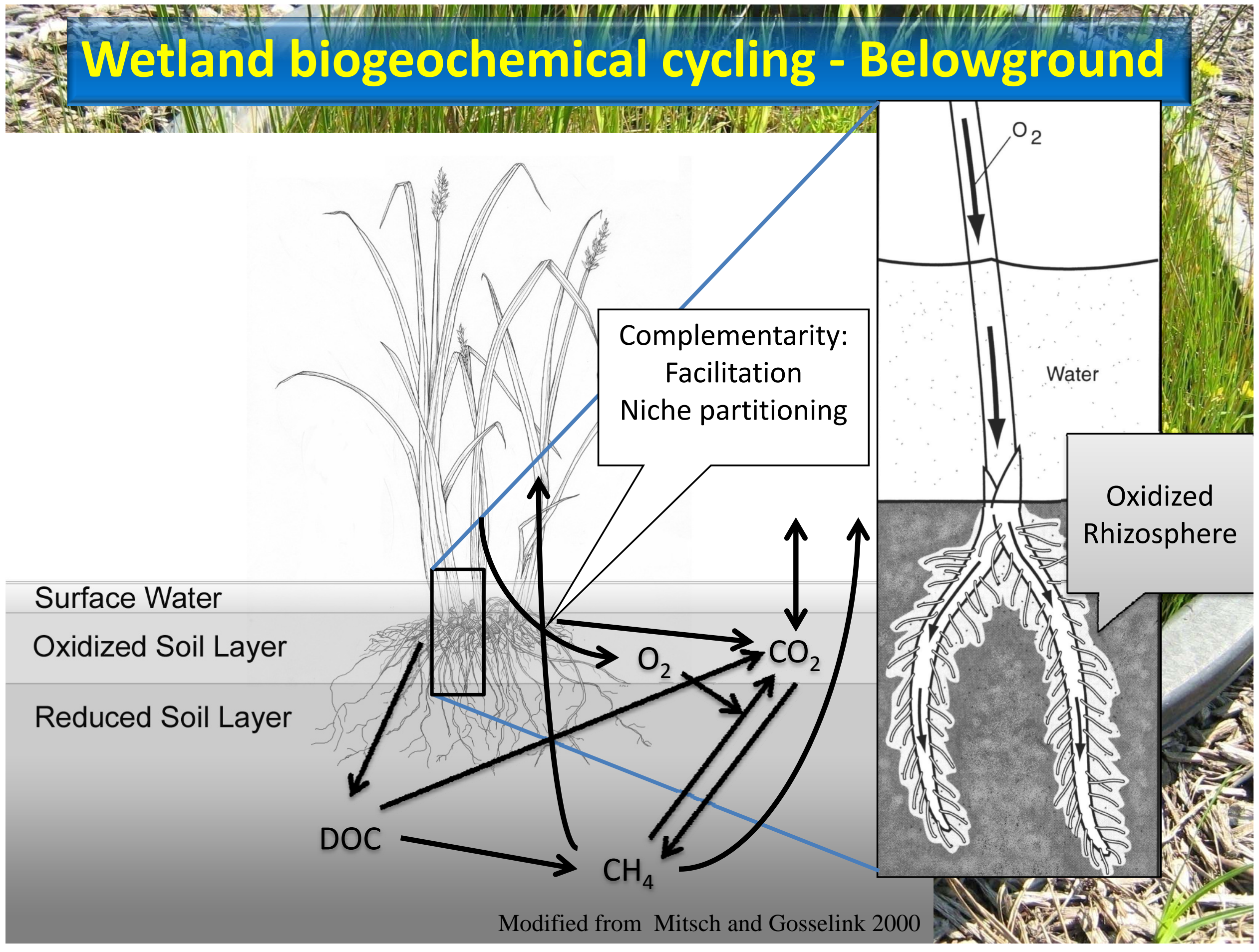




\section{Alternative hypotheses}

A

Root biomass will increase with \# of

FGs due to complementarity
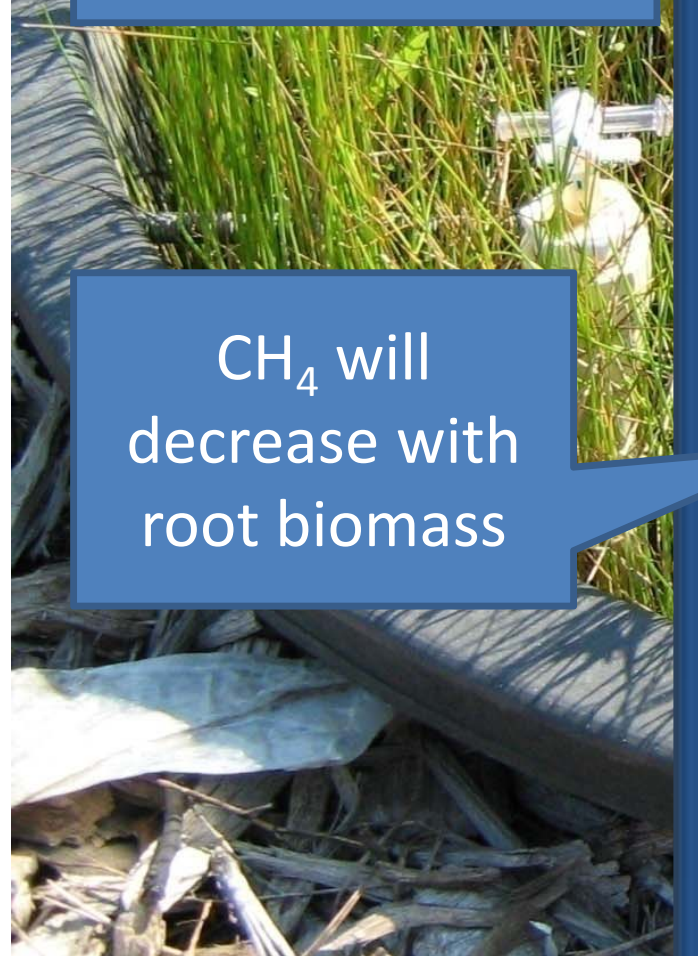

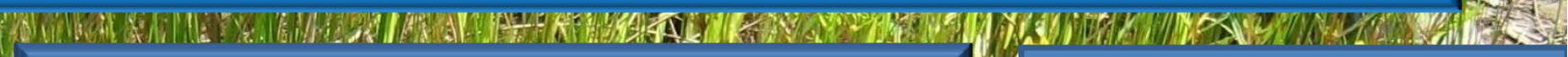
be

Functional Group

Richness

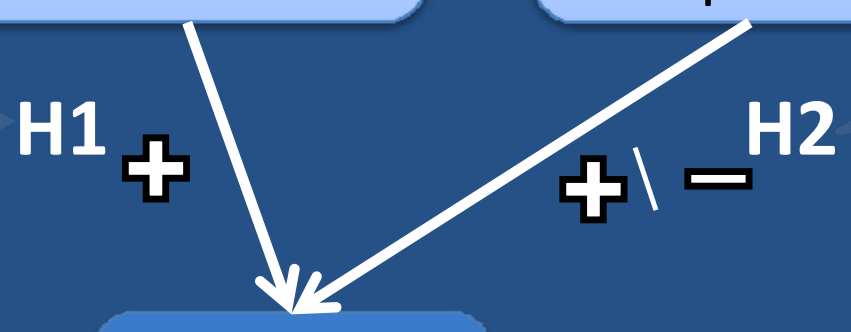

$$
\text { Root }
$$

Biomass

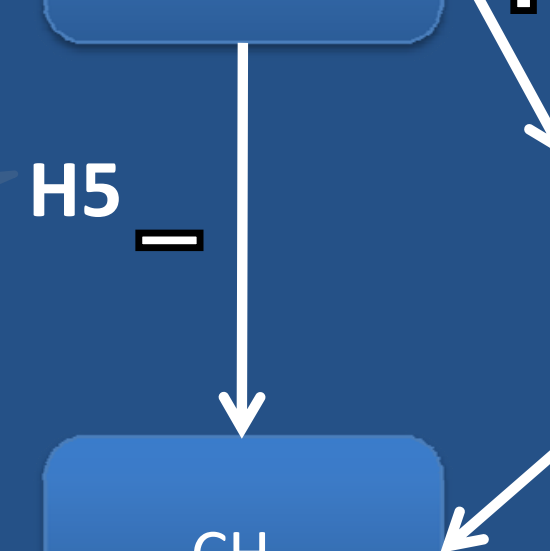

$\mathrm{CH}_{4}$
16 Root biomass will be greater in treatments containing FGs with high productivity

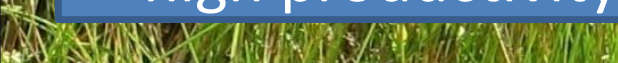
* 1 (N)

DOC will increase with root biomass

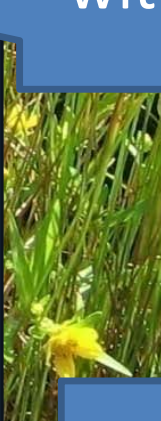

$\mathrm{CH}_{4}$ will increase with DOC 


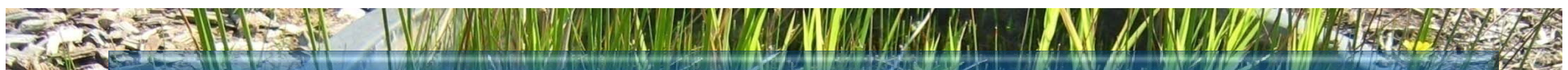

\section{Study Site: Columbus, OH}

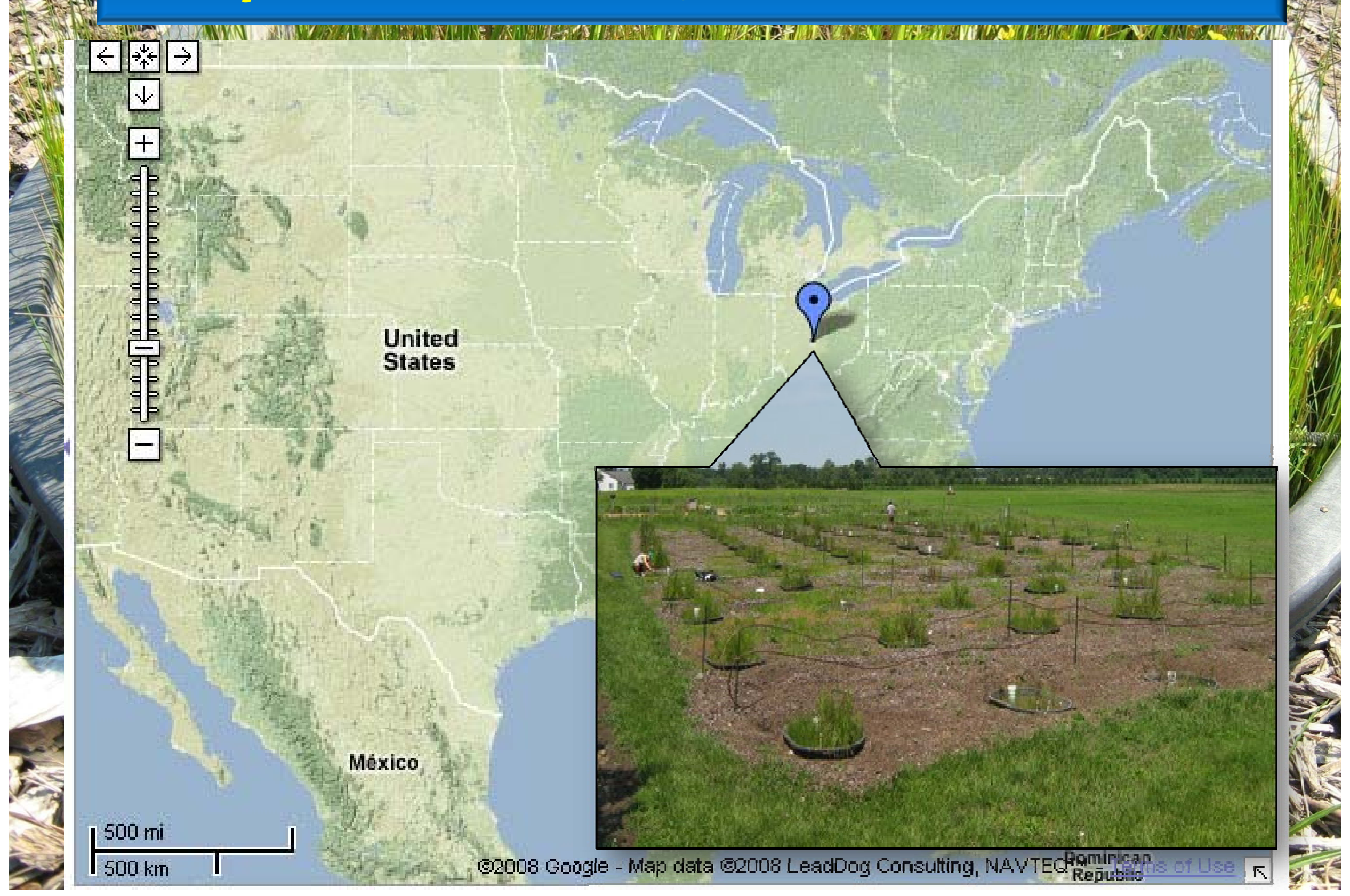




\section{Experimental Design}

Functional Groups (FGs)

(Boutin and Keddy 1993)

$$
\text { * }
$$

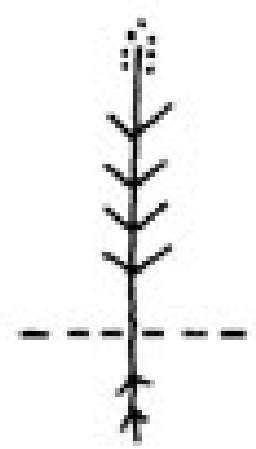

Facultative annuals (FA)
Reeds (R)

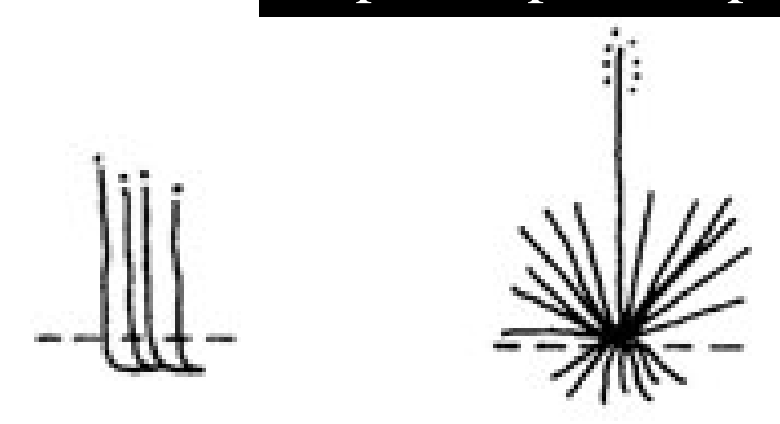

4 species planted per FG

Tussocks (T)

$\square$ Functional group fa; oa; $r$; $t$ (20 mesocosms)

$\square 2$ Functional groups fa+oa; $t+r$; fa+t; fa+r; oa+t, oa+r (30)

$\checkmark 3$ Functional groups fa+oa+t; fa+oa+r; $t+r+o a ; t+r+f a(20)$

$\square$ 4 Functional groups $t+r+o a+f a(5)$

$\square$ Control with no plants (5)

口 Established in 2006 and sampled 2007-2008

*Planted with low organic soil in order to eliminate the carbon artifact from previous vegetation 


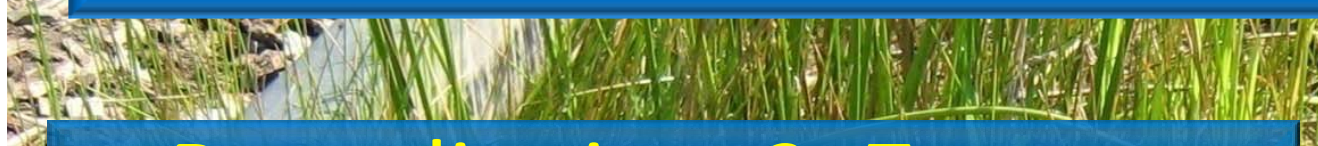

- Post-clipping: $2,7 \mathrm{~cm}$ diameter cores

- every $10 \mathrm{~cm}$ to $30 \mathrm{~cm}$ and homogenized

- Soil washed using a $1 \mathrm{~mm}$ sieve

- Live roots manually separated from detritus and algae

- Roots dried at 55 C for 36 hours

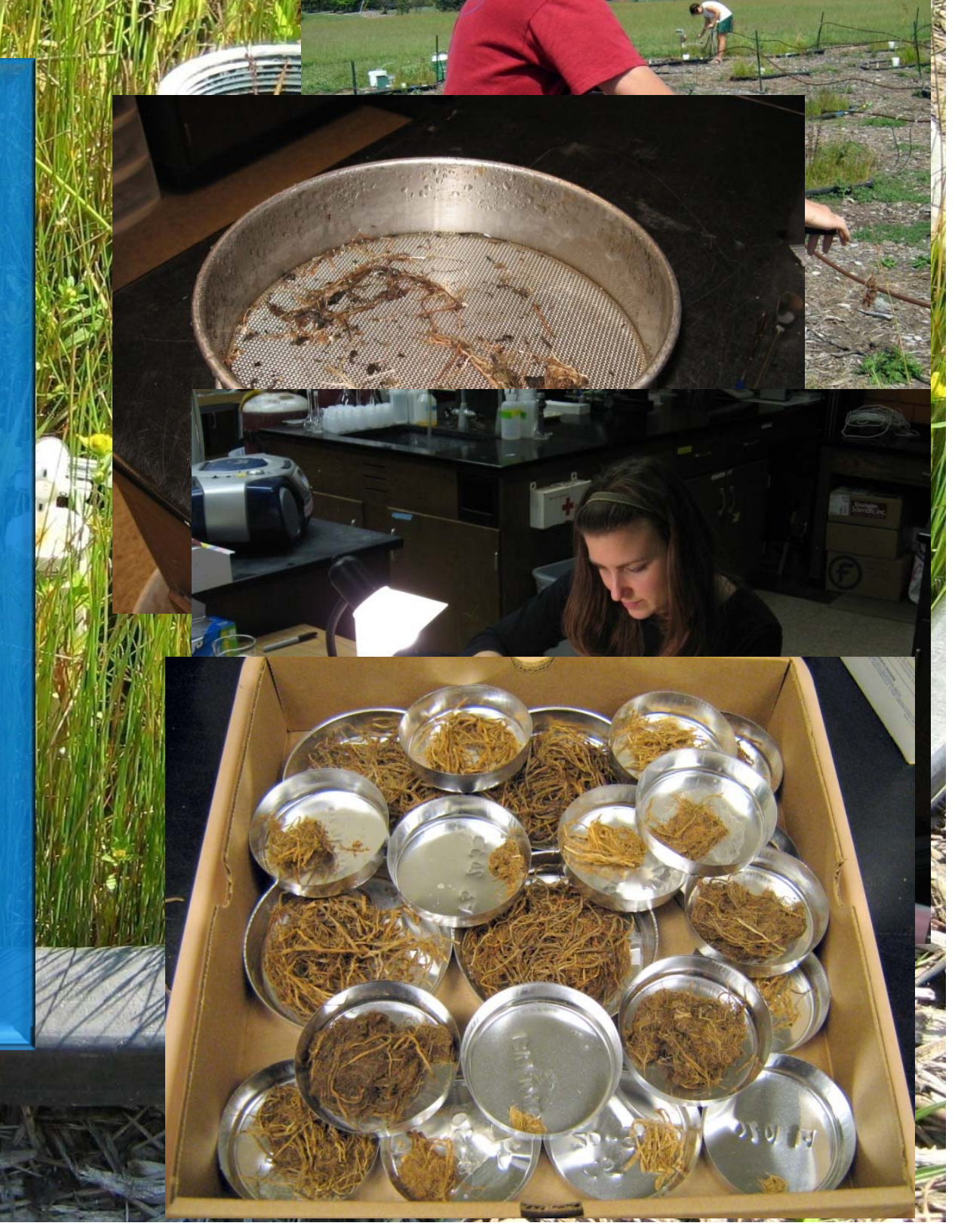




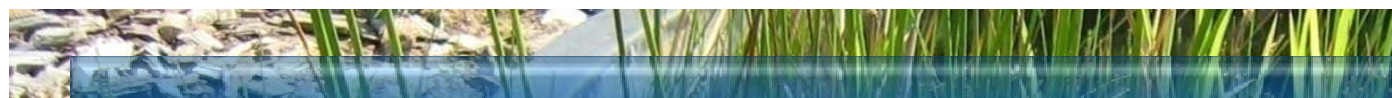

\section{Methods: Porewater}

- Porewater samplers at 5 , 15 , and $25 \mathrm{~cm}$ depths

- 20-25 ml of porewater injected into $\mathrm{N}_{2}$ flushed vials

- Headspace analyzed on a gas chromatograph for $\mathrm{CH}_{4}$

- Filtered (0.4 $\mu \mathrm{m})$ and acidified samples analyzed for DOC (Dohrmann TOC analyzer)
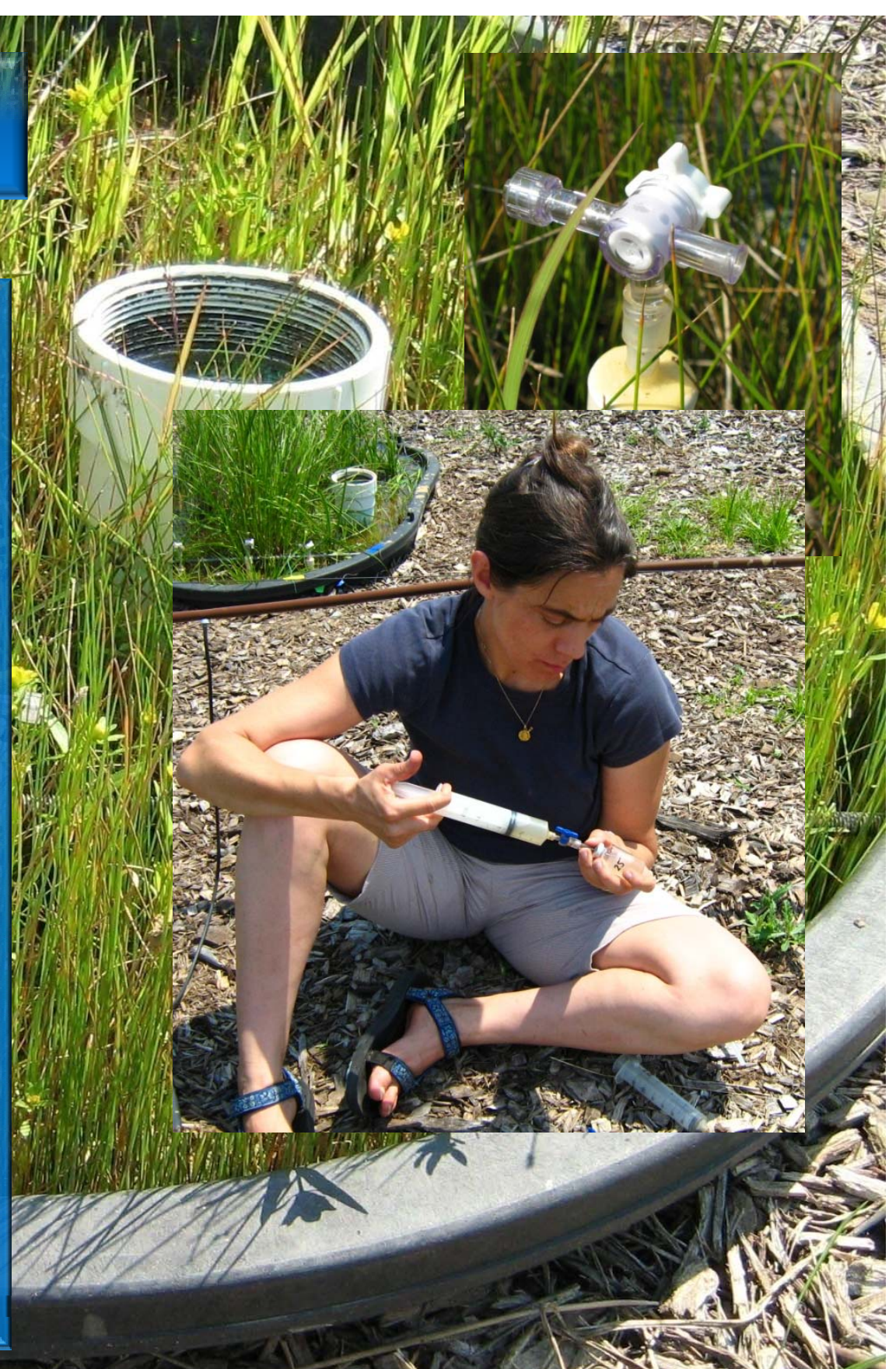

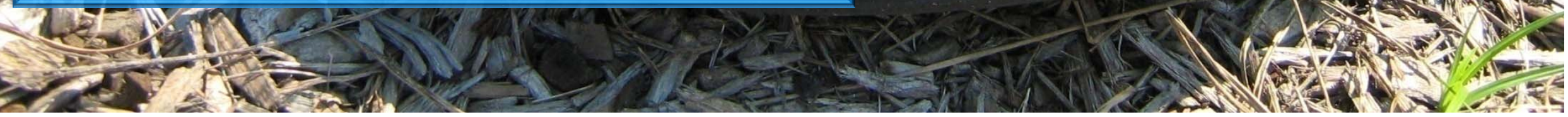




\section{Data Analysis}

- Standard least squares regression (REML method)

- Replicate ID as a random effect

- Fixed effects

- \# of functional groups

- Composition of functional groups within diversity levels

- Depth

- Year or time

- Root biomass for $\mathrm{CH}_{4}$ and DOC

- $\mathrm{DOC}$ for $\mathrm{CH}_{4}$ 


\section{Data analysis (cont.)}

$$
\begin{aligned}
& \text { Partitioning of diversity effects (Loreau and Hector 2001) } \\
& \text { - Net diversity effect }=\Sigma Y_{i}-M_{i} \text {, also } C E+S E \\
& \text { - Complementarity effect }(C E)=N^{*} \overline{\Delta R Y^{*}} \bar{M} \\
& \text { - Selection effect }(S E)=N \operatorname{cov}(\triangle R Y, M)
\end{aligned}
$$

where:

$Y_{i}=$ Observed yield (i.e., root biomass $\mathrm{g} \mathrm{m}^{-2}$ ) for functional group $i$

$M_{i}=$ Monoculture yield for functional group $i$

$\mathrm{N}=$ \# of functional groups in mixture $\Delta$ Relative yield $(\Delta R Y)=\left(Y_{i} / M_{i}\right)-1 / N$ 


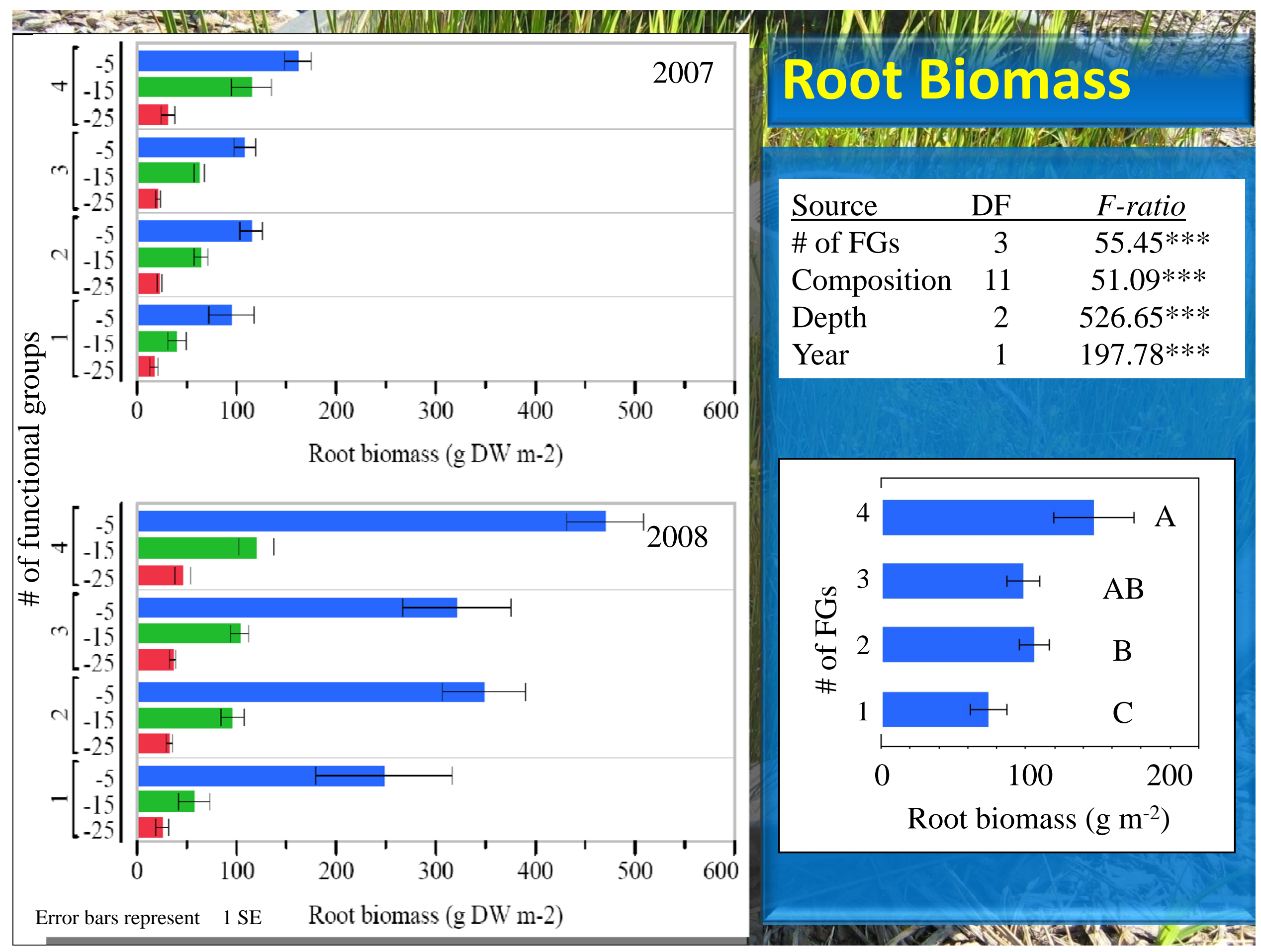




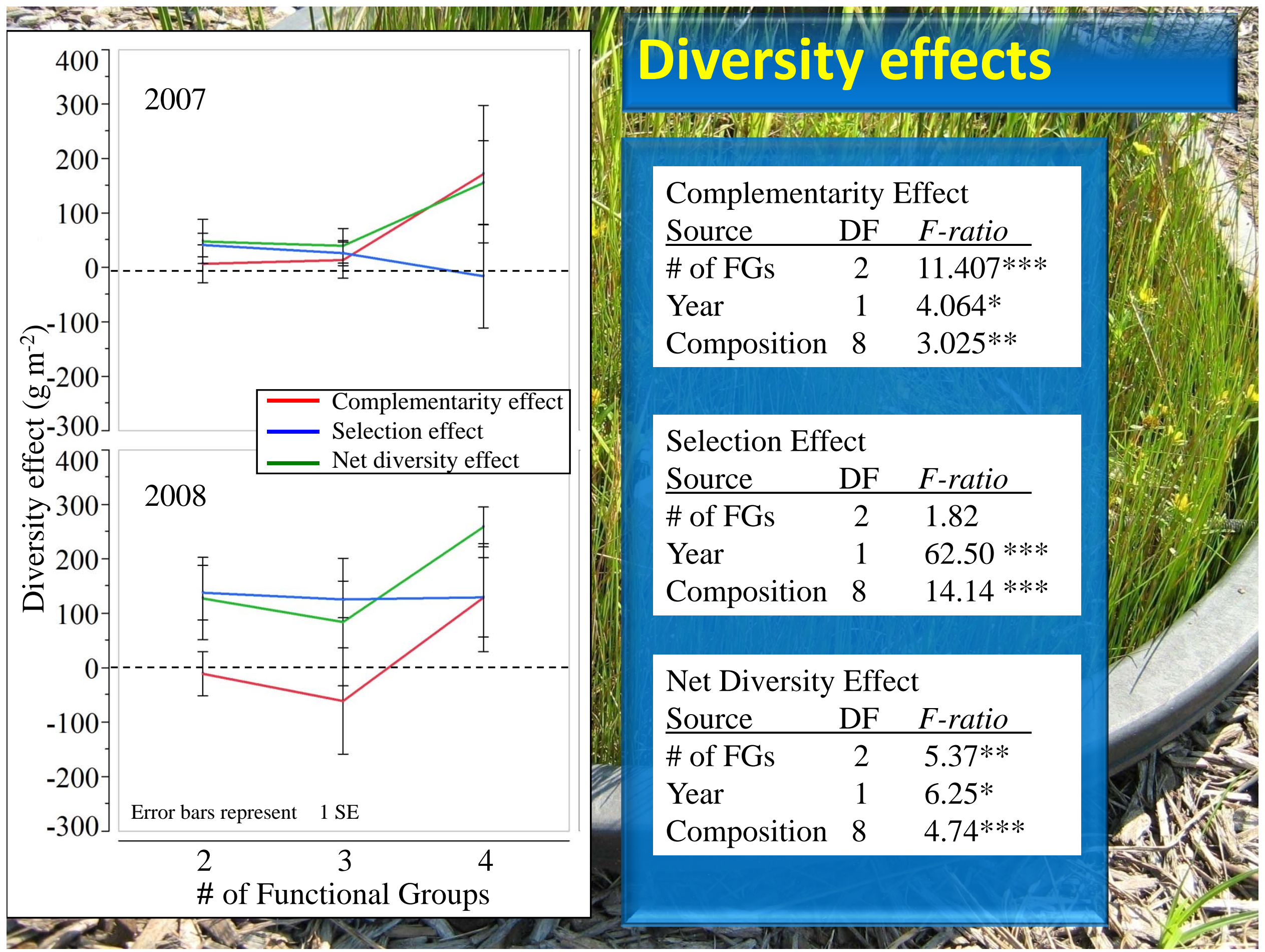




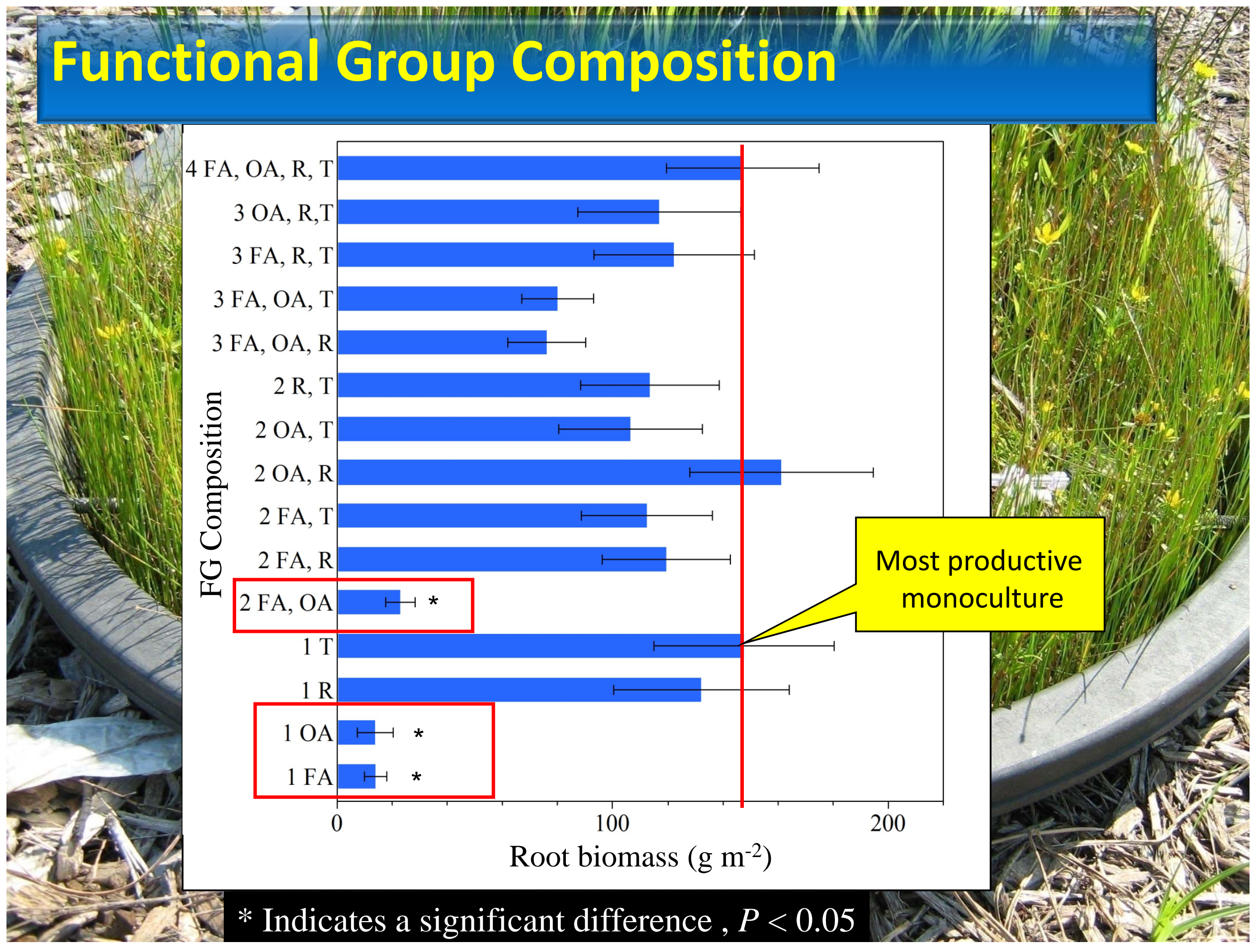




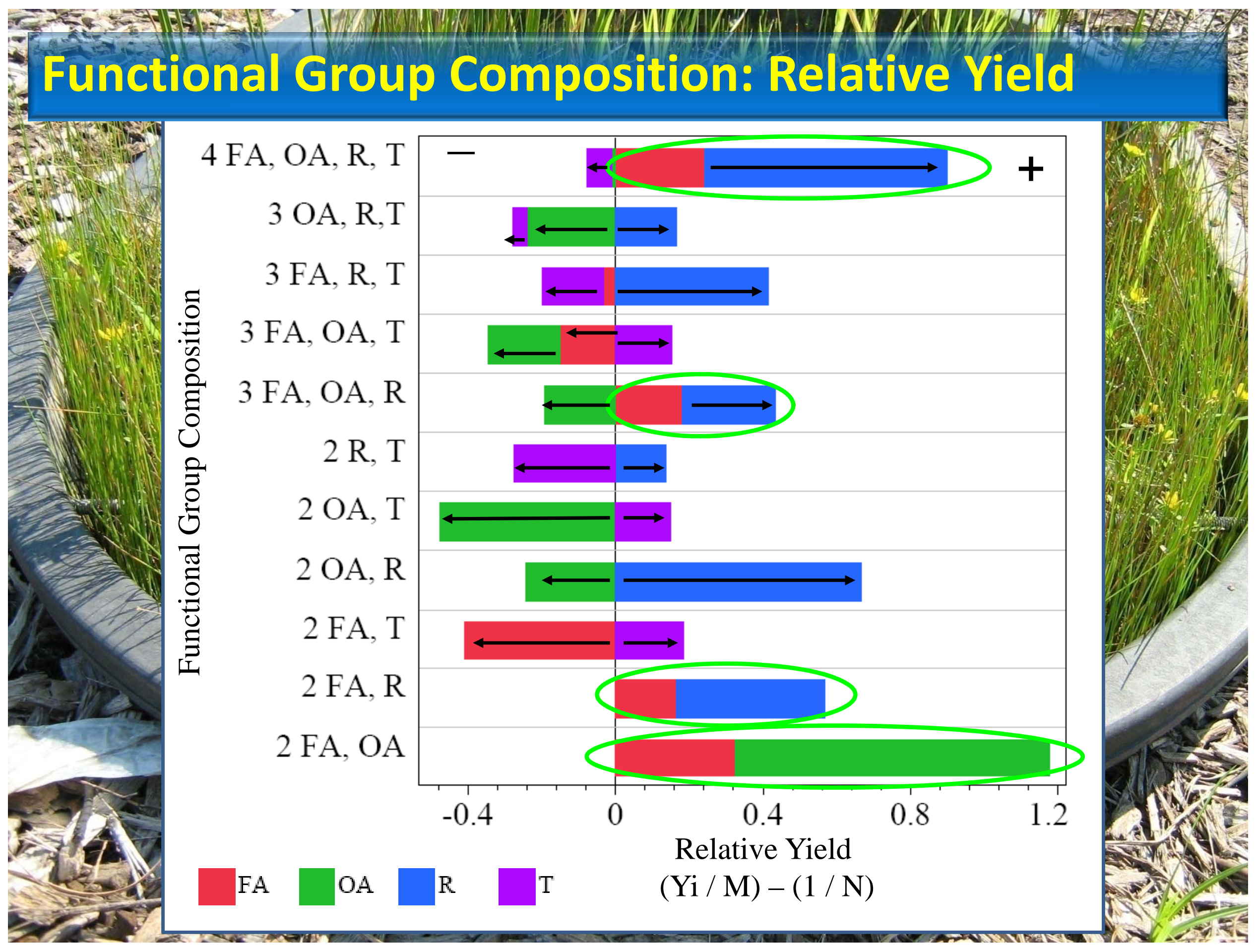




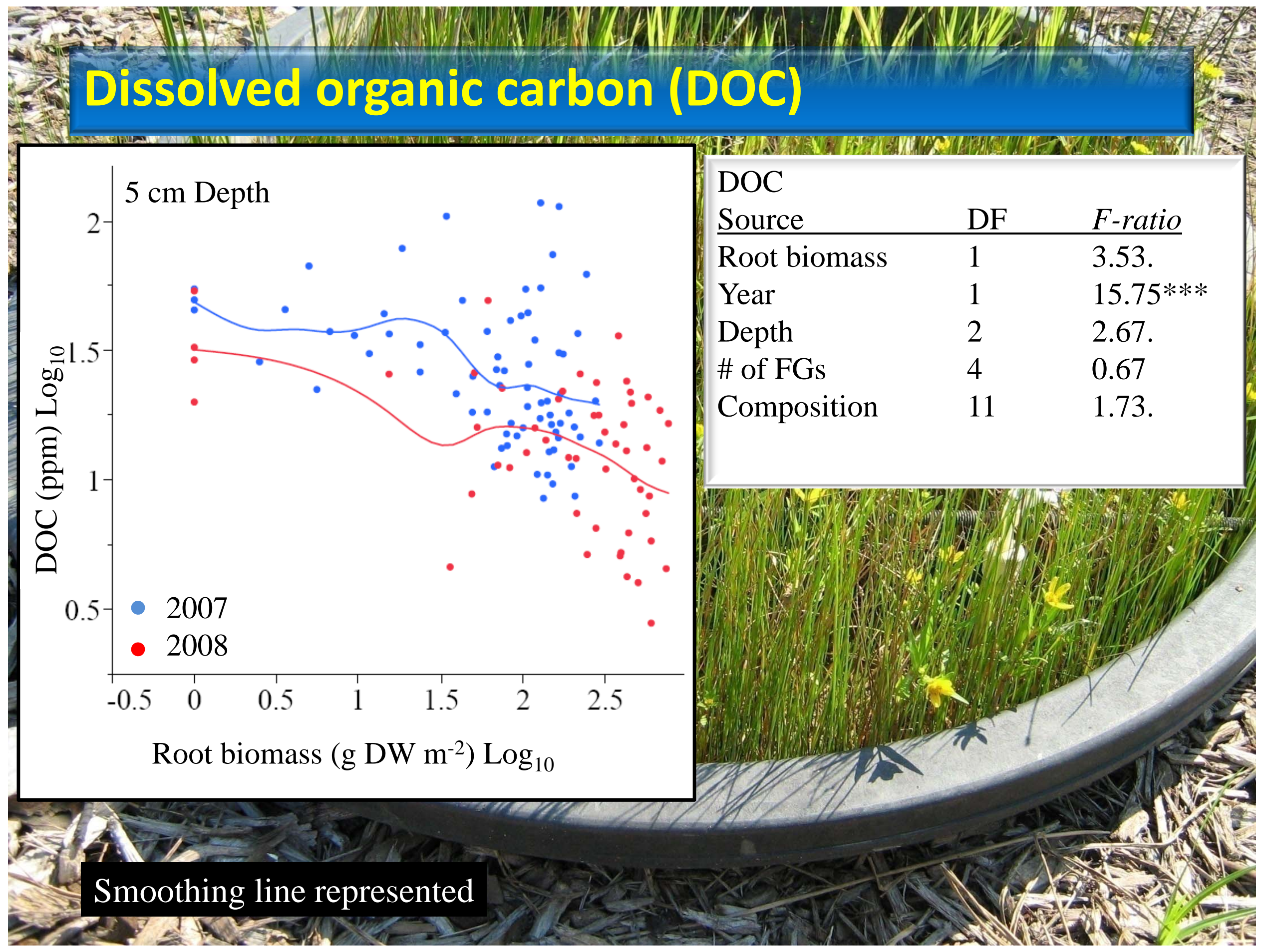




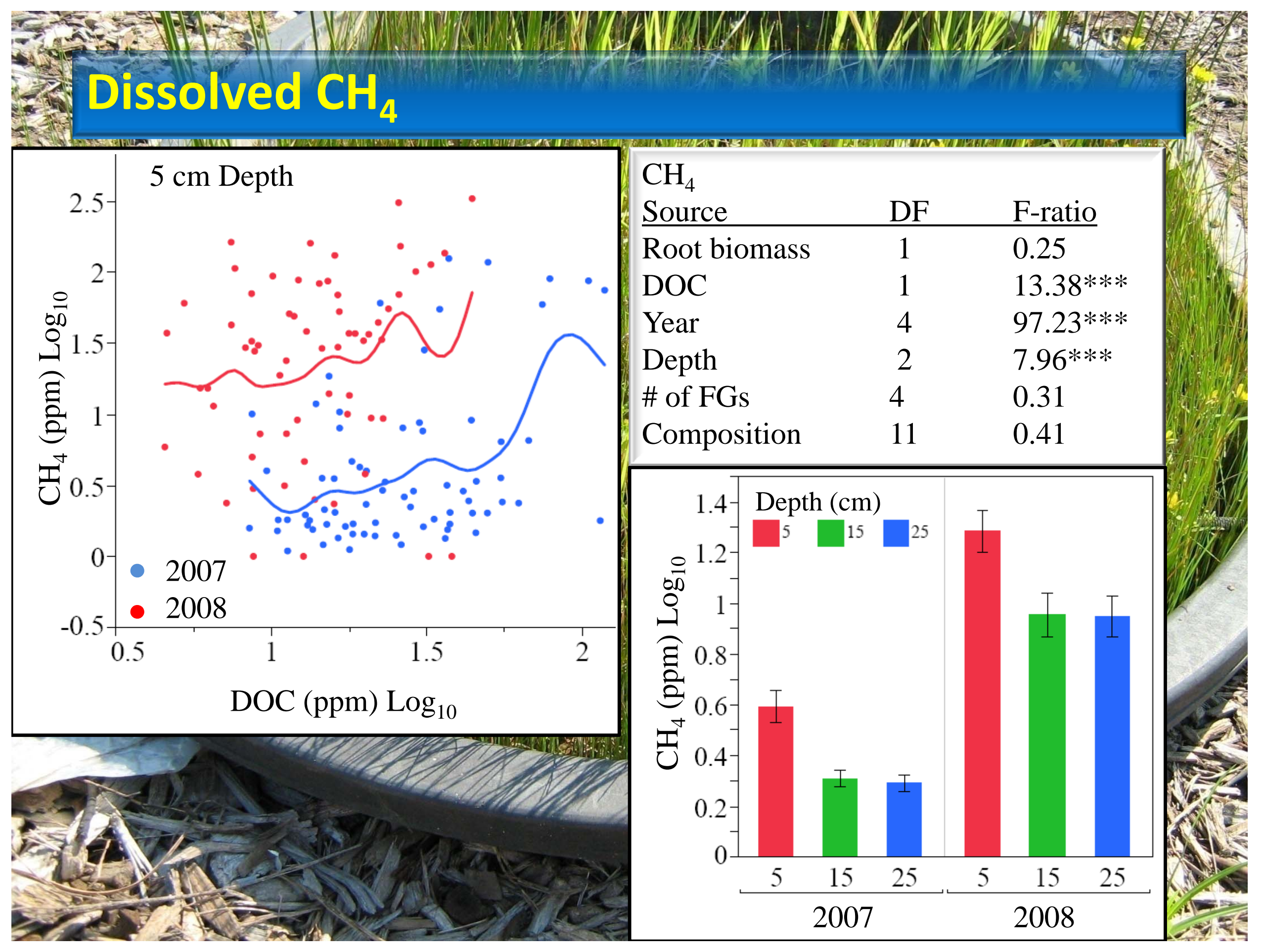


Summary

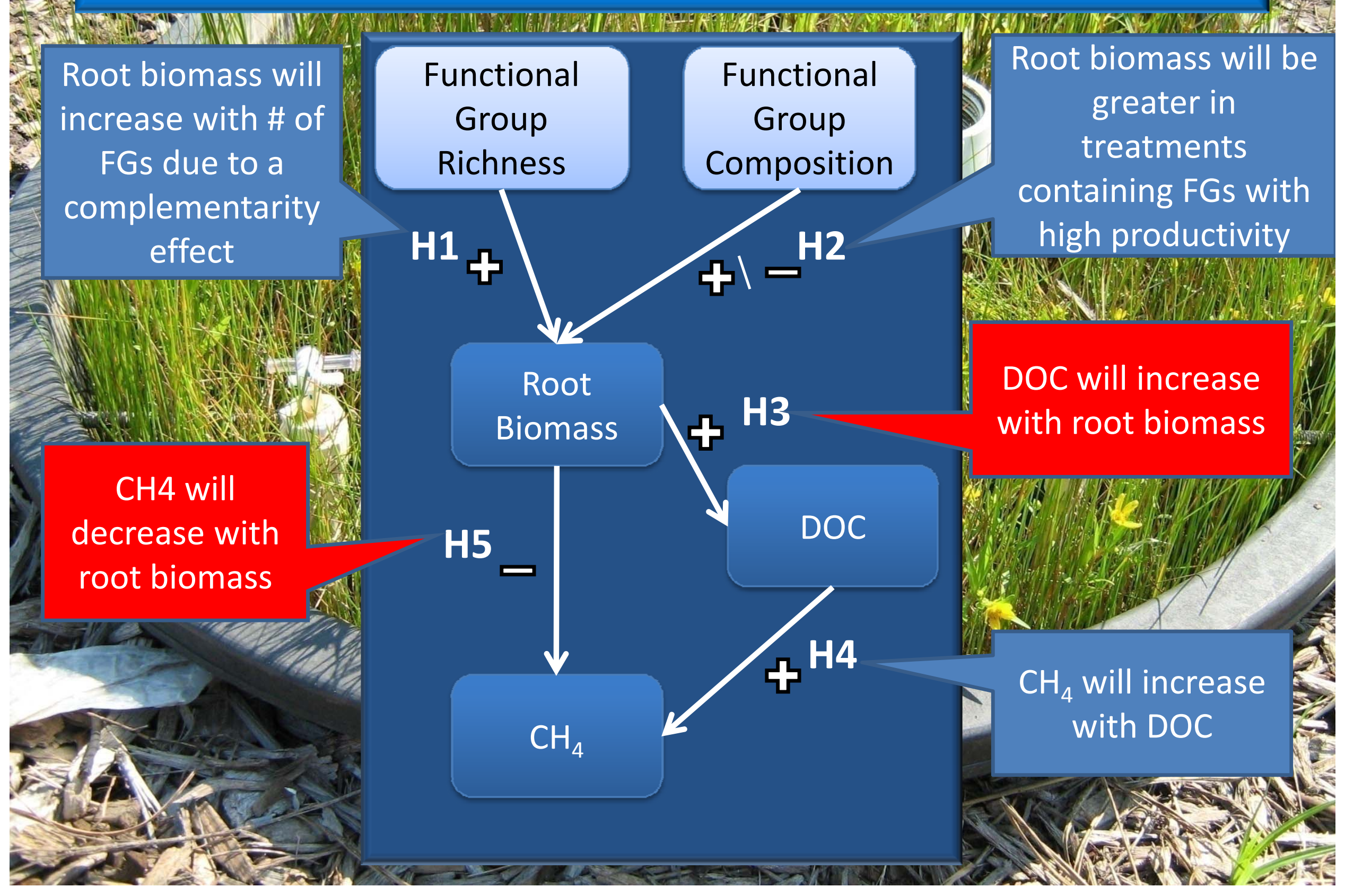




\section{Discuission}

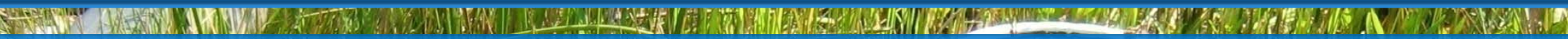

- Belowground productivity

- Complementarity effect at highest diversity level

- Non-transgressive overyielding

- Trend: DOC decreased with root biomass

- Labile carbon is being used up in a low carbon system

- Root surface area vs. biomass (fine roots)

- $\mathrm{CH}_{4}$ dynamic driven by carbon limitation

- The availability of DOC is directly correlated to the sediment pool of $\mathrm{CH}_{4}$

- Fe and S also taking up DOC (reduction by bacteria) 


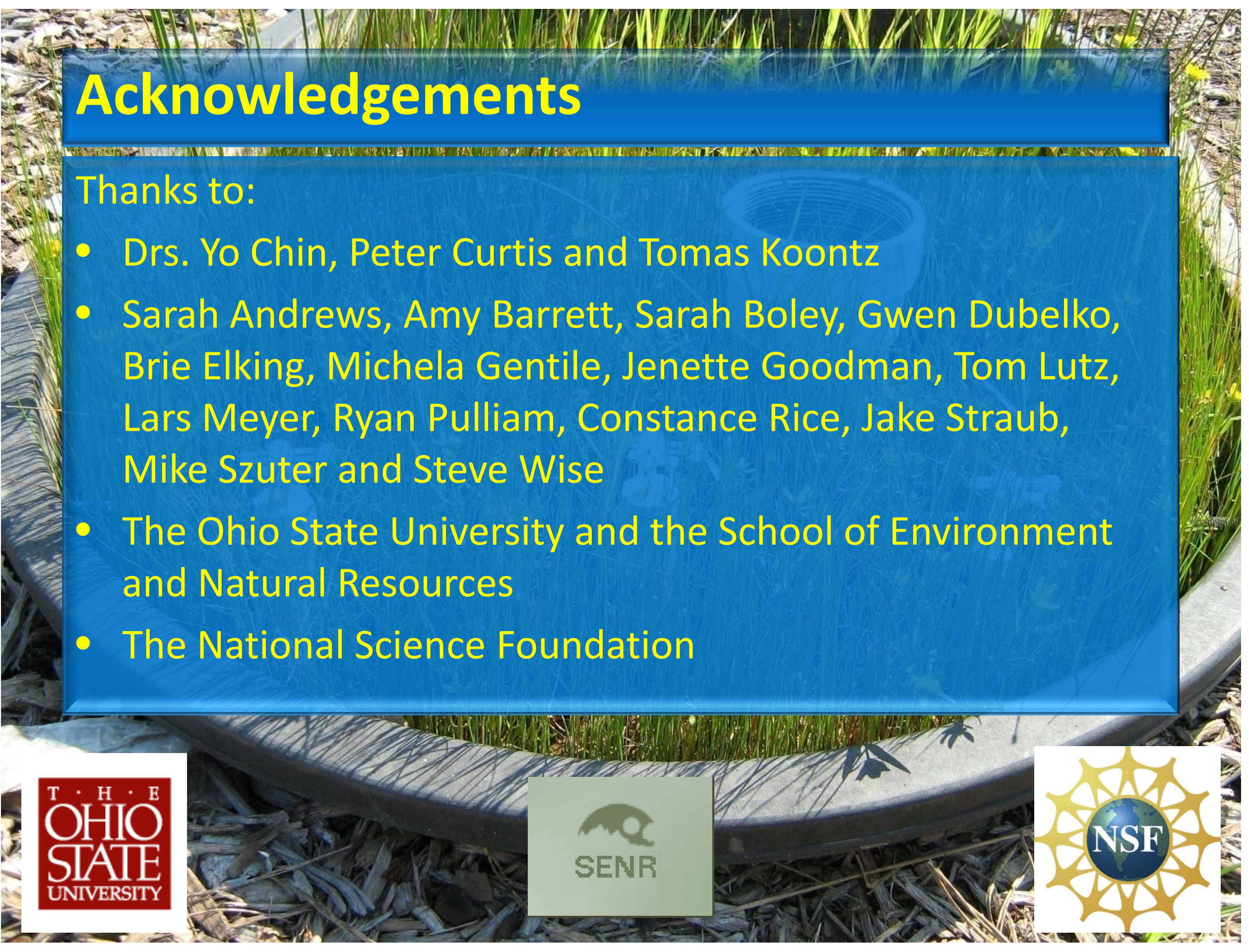




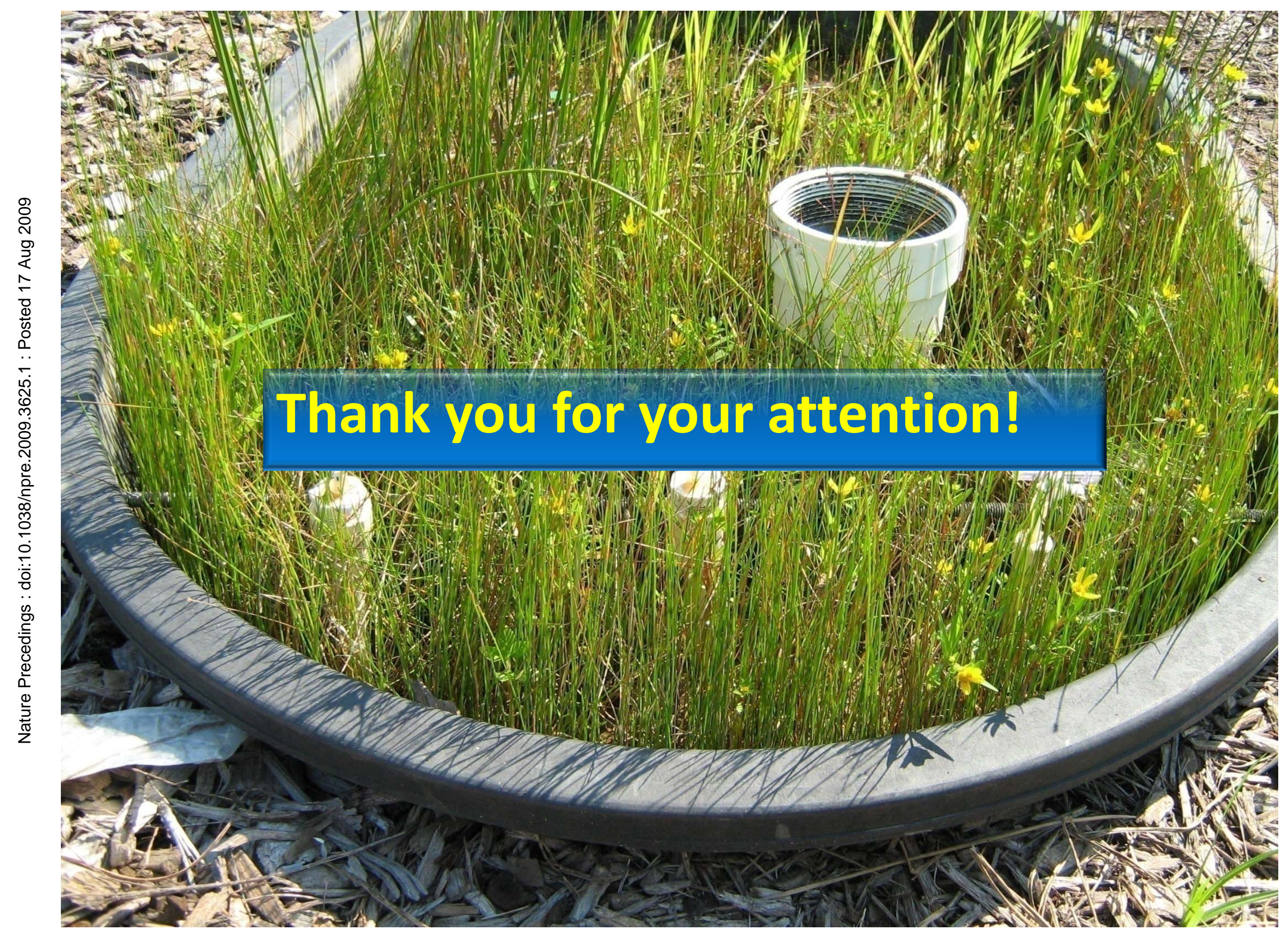

